\title{
Cultivating multiple aspects of attention through mindfulness meditation accounts for psychological well-being through decreased rumination
}

This article was published in the following Dove Press journal:

Psychology Research and Behavior Management

29 June 2015

Number of times this article has been viewed

\section{Jennifer R Wolkin}

Department of Psychiatry, NYU Langone Medical Center, New York, NY, USA

Video abstract

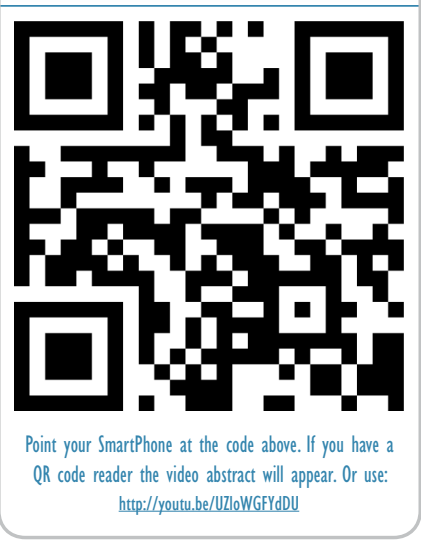

Correspondence: Jennifer R Wolkin Department of Psychiatry, NYU Langone Medical Center, 207 East 84th Street, New York, NY 10128, USA

Email jennifer.wolkin@nyumc.org
Abstract: In the last few decades, mindfulness meditation has gained prominence as an adjunctive psychotherapeutic technique. In fact, a vast literature of controlled studies has found that mindfulness meditation is related to improved mental health across a variety of disorders. Elucidating the components involved in mindfulness meditation's positive impact on psychological well-being is an important step in more precisely identifying the populations that would most benefit from its therapeutic utilization. Yet, a consensus regarding the particular underlying mechanisms that contribute to these outcomes is very much limited. There are many reasons for this, including the inconsistent operationalization and use of mindfulness meditation across research investigations. Despite the elusive mechanisms, many studies seem to indicate that cultivating different aspects of attention is a feasible, consistent, and parsimonious starting point bridging mindfulness practice and psychological well-being. Attention in itself is a complex construct. It comprises different networks, including alerting, orienting, and executive attention, and is also explained in terms of the way it is regulated. This paper supports a previously suggested idea that cultivating all aspects of attention through mindfulness meditation leads to greater psychological well-being through decreased ruminative processes. Ruminative processes are decreased by engaging in both focused and receptive attention, which foster the ability to distract and decenter.

Keywords: mindfulness, attention, rumination, psychological well-being

\section{Introduction}

Meditation is not a monolithic practice, but is a broad term encompassing a multitude of techniques, including mindfulness meditation (MM). From a historical perspective, MM is thousands of years old and stems from ancient Buddhist philosophy. ${ }^{1}$ It was practiced with the goal of experiencing enduring happiness ${ }^{2}$ and the cessation of personal suffering. ${ }^{3,4}$ In the last two decades, MM has received considerable empirical attention, and is currently being promoted as a way to elicit psychological well-being., ${ }^{5,6}$

In fact, a vast literature of controlled studies has found that $\mathrm{MM}$ is related to improved mental health across a variety of disorders, including different anxiety disorders, ${ }^{7-9}$ depression, ${ }^{8,10}$ eating disorders, ${ }^{11,12}$ substance abuse, ${ }^{13}$ and chronic painsymptom reduction. ${ }^{14}$ Also, a recent study alluded to the positive outcomes that mindfulness-based treatment might have on preventing those with mild cognitive impairment from developing Alzheimer's disease. ${ }^{15}$

These studies speak to the positive clinical outcomes resulting from the application of MM to psychological interventions. Knowledge of the underlying mechanisms that contribute to these outcomes is however very much limited. ${ }^{16}$ Elucidating a more 
precise understanding of these mechanisms can likely lead to more precise application of MM across different clinical populations. Despite the clinical importance of delineating possible mechanisms, they are difficult to identify, given limitations to the study of MM as a construct. These limitations will be briefly expanded upon in a later section. Most important for this paper is the variability in the literature with regard to the variability with which MM is operationalized and applied.

Many theoretical frameworks have been set forth hoping to create clarity in operationalizing mindfulness, as well as elucidating its underlying mechanisms. Overall, research indicates that likely several putative mechanisms are involved. However, there also appears to be a consensus that attentional processes are important, acting as an essential bridge connecting mindfulness practice and psychological benefit. ${ }^{17-21}$ For example, Phillipot and Segal assert that attentional control, reflexive awareness, and the capacity to suspend automatic responses reflect processes that promote regulation, which ultimately might account for the psychological benefits of MM.22 Examples of other suggested components will be delineated in a following section. A brief review of the multiple aspects of attention will be discussed later in the paper as well, as it is a complex construct in its own right, and clarification of its components, as well as the way it can be regulated, is often necessary in explaining its relationship with mindfulness and positive clinical outcome. ${ }^{19}$

Rumination, which is the tendency to revisit the same thoughts over and over again, often reflects a process during which attention is not intentionally directed. ${ }^{23}$ Deficits in sustained attention ${ }^{24}$ and set-shifting difficulties have been linked to many different forms of psychological difficulty. ${ }^{25}$ Notably, the same populations exhibiting these difficulties are more likely to ruminate. ${ }^{26}$ This paper proposes that the cultivation of many aspects of attention, as well as its ability to be regulated, leads to a reduction in ruminative thinking.

Taking the process further, this paper proposes that MM works in two ways to decrease rumination: 1) distraction is employed via the deliberate shift of attention from ruminative thoughts to the immediate here-and-now experience (ie, the breath), and 2) decentering is enabled, allowing for a shift from the content of the rumination to the nonjudgmental acceptance of the presence of transient thoughts. Both distraction and decentering are intricately connected with the regulation of focused attention (FA) and receptive attention (RA), respectively.

In summary, this review: 1) briefly reviews why defining mindfulness and therefore parsing its underlying mechanisms is challenging, 2) delineates different formulations of the components accounting for mindfulness's impact on psychological well-being, 3) highlights and then proposes that an attention-based model is most consistent and salient in accounting for MM's positive psychological well-being outcomes, and 4) parses out a previously suggested but littleresearched idea that cultivating aspects of attention through mindfulness leads to psychological well-being by way of decreasing ruminative processes.

\section{Materials and methods}

Studies were identified using PubMed, PsycInfo, and Google Scholar using the following keywords both alone and in combination: mindfulness, meditation, attention, executive attention, attentional control, rumination, psychological functioning, psychological well-being. A manual review of references for each identified study and review paper was also conducted. Note that mindfulness practice and MM are used interchangeably here unless specifically stated otherwise.

\section{Limitations to studying underlying mechanisms}

Many MM studies have been criticized for their methodological limitations, which make it more difficult to elucidate underlying mechanisms. Many studies lacked control groups, were not randomized, used a "wait list" comparator, utilized different instruments to measure mindfulness, and predominantly relied on self-report. ${ }^{27}$ Most studies were crosssectional, and thus precluded interpretation that there was some kind of causative effect or that elucidated factors could be maintained over time. Additionally, studies failed to take into account the length of practice (daily and total) needed, ${ }^{19} \mathrm{a}$ priori meditation experience, ${ }^{28,29}$ and possible inherent attraction and openness to specific kinds of practice. ${ }^{27}$

Another limitation across the literature is the significant variance regarding the theoretical and actionable applications of MM as an intervention in psychological settings. This manifests in multiple ways.

First, the idea of mindfulness has become a colloquialism, and both MM and the word "mindfulness" are often used interchangeably. Technically, the former is an actual practice (action) utilized to cultivate the latter (state), which has often been characterized by an awareness of the internal and external present-moment milieu without engaging with it. ${ }^{30}$ In addition to being described as an actionable and traditional meditation practice, and as a state that is cultivated, the word "mindfulness" is also sometimes used to describe a dispositional psychological trait or an intervention. Therefore, the term "mindfulness" is often used loosely in the literature 
without differentiation, perhaps because there is considerable overlap between the four concepts. ${ }^{31}$

Second, many systematic differences in mindfulness-based protocols exist, and mindfulness-based psychological interventions encompass a wide range of practices. More traditional MM practices involved in cultivating mindfulness are differentiated from mindfulness-based interventions (MBIs), ${ }^{32}$ which include current adaptations applied to psychological settings. More traditional MM practices, including Vipassana meditation, ${ }^{33}$ originated thousands of years ago. They stem from ancient Buddhist philosophy, and are associated with long-term consistent practice geared toward spiritual development and a greater understanding of the universe. ${ }^{34}$ In the last few decades, MBIs have been stripped of any spiritual, religious, or moral context, and adapted to heal a variety of psychological conditions. For example, mindfulness training has most recently been incorporated into clinically oriented group-based meditation programs, including mindfulnessbased stress reduction (MBSR), ${ }^{35}$ which was the first MBI.

However, even within the rubric of MBIs, there are differences. Some rely on the meditative practice of mindfulness, including $\mathrm{MBSR}^{35}$ and mindfulness-based cognitive therapy (MBCT). ${ }^{36}$ Others, such as dialectical behavior therapy (DBT) $)^{37}$ and acceptance and commitment therapy (ACT), ${ }^{38}$ are consistent with broad contemporary conceptualizations of mindfulness, but do not rely heavily on actual meditative practice.

The heterogeneity in the utilization of different MBIs makes it difficult to parse out particular mechanisms responsible for the clinical outcomes of MM. This variance is elucidated in Chiesa et al's systematic review of neuropsychological outcomes of mindfulness in 23 studies. ${ }^{39}$ Of those 23,15 were described as either prospective controlled or randomized controlled studies providing objective measures of cognition following MM. However, two studied the effects of MBSR, ${ }^{40,41}$ and three studied the effects of MBCT, ${ }^{42-44}$ Others studied the outcomes after a Vipassana retreat, ${ }^{45,46}$ a brief nonspecific retreat, ${ }^{47}$ breathing programs ${ }^{48}$ sometimes labeled as "mindful breathing", ${ }^{49}$ or $\mathrm{MM},{ }^{50}$ mindfulness induction,,${ }^{51}$ and MM practice. ${ }^{52}$ McMillan et $\mathrm{al}^{53}$ studied the effects of acceptance and commitment therapy, and Jha et $\mathrm{al}^{40}$ studied the effects of mindfulness-based mental fitness training.

\section{Proposed components of mindfulness meditation}

Many different researchers have proposed conceptualizations of mindfulness that account for the components of MM involved in mediating psychological well-being (Table 1).
Table I Proposed components of mindfulness meditation

\begin{tabular}{|c|c|c|}
\hline Author(s) & $\begin{array}{l}\text { Proposed components of } \\
\text { mindfulness meditation }\end{array}$ & $\begin{array}{l}\text { Direct } \\
\text { attentional } \\
\text { component? }\end{array}$ \\
\hline Kabat-Zinn ${ }^{35}$ & $\begin{array}{l}\text { I. Attentional skills and } \\
\text { 2. Development of a nonjudgmental } \\
\text { attitude toward one's experiences }\end{array}$ & $\nabla$ \\
\hline $\begin{array}{l}\text { Brown and } \\
\text { Ryan }^{17}\end{array}$ & $\begin{array}{l}\text { I. Attention to and awareness of } \\
\text { moment-to-moment experience }\end{array}$ & $\nabla$ \\
\hline Bishop et $\mathrm{al}^{5}$ & $\begin{array}{l}\text { I. Paying attention to the here and now } \\
\text { 2. An orientation of curiosity, } \\
\text { openness, and acceptance }\end{array}$ & $\nabla$ \\
\hline $\begin{array}{l}\text { Shapiro } \\
\text { et al }{ }^{18}\end{array}$ & $\begin{array}{l}\text { I. Intention } \\
\text { 2. Attention } \\
\text { 3. Attitude }\end{array}$ & $\nabla$ \\
\hline Baer et $\mathrm{al}^{54}$ & $\begin{array}{l}\text { I. Observing (attending to internal } \\
\text { and external stimuli) } \\
\text { 2. Describing } \\
\text { 3. Acting with awareness } \\
\text { 4. Nonjudgment of inner experience } \\
\text { 5. Nonreactivity to inner experiences }\end{array}$ & $\nabla$ \\
\hline $\begin{array}{l}\text { Hölzel } \\
\text { et } \mathrm{al}^{21}\end{array}$ & $\begin{array}{l}\text { I. Attention regulation } \\
\text { 2. Body awareness } \\
\text { 3. Emotion regulation } \\
\text { 4. Change in perspective on the self }\end{array}$ & $\nabla$ \\
\hline Farb et $\mathrm{al}^{55}$ & $\begin{array}{l}\text { I. Attention to present-moment } \\
\text { sensation } \\
\text { 2. A sense of equanimity }\end{array}$ & $\nabla$ \\
\hline $\begin{array}{l}\text { Vago and } \\
\text { Silbersweig }\end{array}$ & $\begin{array}{l}\text { I. Intention and motivation } \\
\text { 2. Attention and emotion regulation } \\
\text { 3. Extinction and reconsolidation } \\
\text { 4. Prosociality } \\
\text { 5. Nonattachment and } \\
\text { 6. Decentering }\end{array}$ & $\nabla$ \\
\hline
\end{tabular}

Approximately two decades ago, John Kabat-Zinn, the pioneer of MM's clinical use, introduced MBSR, ${ }^{35}$ which was developed to facilitate psychological well-being via two central components: 1) attentional skills and 2) development of a nonjudgmental attitude toward one's experiences. More specifically, Kabat-Zinn ${ }^{35}$ described mindfulness as a state of sustained attention to present-moment internal processes (thoughts, feelings, physical sensations) with acceptance and without judgment. Bishop et al proposed a similar model, which was described as paying attention to the here and now with an orientation of curiosity, openness, and acceptance. ${ }^{5}$

According to Brown and Ryan, mindfulness is a single factor construct described as attention to and awareness of moment-to-moment experience. ${ }^{17}$ Shapiro et al described three axioms of mindfulness: intention, attention, and attitude. $^{18}$ 
Baer et al conceptualized mindfulness as a five-factor phenomenon composed of correlated skills: 1) observing (attending to internal and external stimuli), 2) describing (mentally labeling these stimuli with words), 3) acting with awareness (attending to one's current actions, as opposed to behaving automatically), 4) nonjudgment of inner experience (refraining from evaluation of one's sensations, cognitions, and emotions), and 5) nonreactivity to inner experiences (allowing thoughts and feelings to come and go, without attention caught in them). ${ }^{54}$

Hölzel et al suggested that the benefits of MM are produced by a combination of distinct but interactive components, including 1) attention regulation, 2) body awareness, 3 ) emotion regulation (including reappraisal, exposure, extinction, and reconsolidation), and 4) change in perspective on the self. ${ }^{21}$

Farb et al asserted that mindfulness relies on attention to present-moment sensation and encompasses a sense of equanimity, which refers to the deferral of judgmental labeling of experiences (ie, "this thought is neither good nor bad"). ${ }^{55}$

Vago and Silbersweig suggested a model of MM that describes six neurocognitive component mechanisms that are highly integrated: 1) intention and motivation, 2) attention and emotion regulation, 3) extinction and reconsolidation, 4) prosociality, 5) nonattachment, and 6) decentering. ${ }^{56}$

Most of these conceptualizations include multiple contributing factors, but the cultivation of attentional skills appears to be a consistent factor throughout this literature (Table 1). According to Carmody, ${ }^{20}$ mechanisms of attention are the most parsimonious starting point from which other mechanisms of mindfulness can be extrapolated. Chiesa and Malinowski ${ }^{57}$ also indicate that cultivating skills of attention may underlie all other mechanisms that lead to psychological well-being. For example, it is through the cultivation of attentional regulation that a nonjudgmental vantage point toward experiences would even be possible. ${ }^{19}$

The feasibility of this conceptualization is also reflected in van de Weijer-Bergsma et al's study, during which the subjects - adolescents with attention and impulse difficulties - performed better than baseline scores on sustained attention tasks subsequent to mindfulness training. ${ }^{58}$ Ellenbogen et a ${ }^{59}$ indicated in their study that after attention was deliberately directed to the neutral word of a neutral-negative word pair, subjects reported less negative affect when exposed to a subsequent mental stressor. This research makes a case for prioritizing the development of attentional skills as a consistent model considered to be fundamental to MM's contribution to positive psychological outcomes.

\section{Mindfulness meditation and attentional networks}

Like MM itself, attention is not easily defined. Over two decades ago, Posner and Petersen conveyed their conceptualization of attention as a multifaceted construct made up of the three unique and differentiated yet overlapping networks called alerting, orienting, and executive attention (Table 2) ${ }^{60}$ The relationship between all three attentional networks is still not entirely known, ${ }^{61}$ but mindfulness practice has been linked to improvement in all three.

Alerting, often referred to as vigilance, is identified as the most basic of the networks, and is associated with the ability to sustain and maintain attention over long periods of time. ${ }^{60,62}$ In MM, sustained attention is necessary for one to maintain awareness of a present-moment experience or on a specified object of attention (ie, the breath). ${ }^{5}$

Orienting, sometimes called selective attention, ${ }^{63}$ is either the reflexive or purposeful selection of specific sensory information within the context of a high-volume sensory experience. ${ }^{62,64}$ It is the way in which sensory input is selected, thereby limiting attention to a subset of possible sensorial inputs. It is often recognizable by head and eye movements toward the selected target. ${ }^{64,65}$ Phillipot and Segal suggested that MM entails the intentional placement of attention, and thus the ability to orient attention toward a specified object. ${ }^{22}$

Executive attention, sometimes called conflict monitoring, or switching, allows for the prioritization of attention in the context of competing cognitive demands: one can preferentially shift focus from one thing to another. Recently, Petersen and Posner presented an expanded model, which supports the conceptualization of two separate orienting and two separate executive networks, each with specific functions. ${ }^{64}$ The extended model also elucidates the key players in the executive attention network, including self-regulation, cognitive flexibility, and metacognitive awareness (Table 3). These components

Table 2 Attention networks

\begin{tabular}{|c|c|c|}
\hline $\begin{array}{l}\text { Attention } \\
\text { networks }\end{array}$ & Also known as & Definition \\
\hline Alerting & $\begin{array}{l}\text { Vigilance, sustained } \\
\text { attention }\end{array}$ & $\begin{array}{l}\text { The ability to maintain attention } \\
\text { over long periods of time }\end{array}$ \\
\hline Orienting & $\begin{array}{l}\text { Selective attention, } \\
\text { divided attention }\end{array}$ & $\begin{array}{l}\text { The ability to limit attention to a } \\
\text { subset of possible sensory inputs }\end{array}$ \\
\hline $\begin{array}{l}\text { Executive } \\
\text { attention }\end{array}$ & $\begin{array}{l}\text { Conflict monitoring, } \\
\text { attention switching }\end{array}$ & $\begin{array}{l}\text { The ability to prioritize attention } \\
\text { in the context of competing } \\
\text { cognitive demands }\end{array}$ \\
\hline
\end{tabular}


of executive attention are closely linked, and sometimes only subtle nuances distinguish between their functionality. ${ }^{18}$ Posner and Rothbart concluded that executive attention is the glue that holds together all self-regulatory processes. ${ }^{66}$

Self-regulation, often called self-control, is defined as the ability to monitor and modulate cognition, emotion, and subsequent behavior. ${ }^{64,67}$ Emotional self-regulation allows for the malleability of internal emotional responses to stressful situations ${ }^{68}$ whereas cognitive self-regulation can include the regulation of overt behaviors. ${ }^{69}$ Intact ability to self-regulate is an essential human skill that has even been cited as a core mechanism by which the personal "self" is constructed..$^{70}$ This underscores the need to cultivate self-regulation's adaptive functioning, as failure to do so underlies psychological distress. Kabat-Zinn et al linked MM with the self-regulation of chronic pain. ${ }^{71}$

As described by Moore and Malinowski, cognitive flexibility is the ability to adapt to new and unexpected conditions. $^{72}$ Similarly, Mirsky et al associated cognitive flexibility with the ability to adaptively change attentional focus. ${ }^{73}$ This ability is particularly relevant in MM, given the constant need to invest and reinvest attention to the present moment. ${ }^{74}$ Cognitive flexibility is often assessed with the Stroop task ${ }^{75}$ which measures the extent to which interfering information impinges upon attentional focus. Studies have linked mindfulness with improved cognitive flexibility, and thus with the reduction of interference on the Stroop task. ${ }^{49}$

Metacognition has been defined as thinking about thinking. ${ }^{76}$ It is the conscious awareness of cognitive processes as they are occurring, and is often referred to as reperceiving or decentering. ${ }^{77}$ Decentering connotes a shift in perspective from a subjective relationship with experiences to one that is more objective. Thoughts, feelings, and cognitions are less narrowly contextualized within a personal framework. The ability to decenter has been linked to mindfulness training. ${ }^{77}$

Table 3 Executive attention components

\begin{tabular}{|c|c|c|}
\hline $\begin{array}{l}\text { Executive } \\
\text { attention }\end{array}$ & $\begin{array}{l}\text { Also } \\
\text { known as }\end{array}$ & Definition \\
\hline $\begin{array}{l}\text { Cognitive } \\
\text { flexibility }\end{array}$ & Set-shifting & $\begin{array}{l}\text { The ability to shift from one thought } \\
\text { to another and/or to have multiple } \\
\text { thoughts in mind at one time }\end{array}$ \\
\hline Self-regulation & $\begin{array}{l}\text { Self-control, } \\
\text { willpower }\end{array}$ & $\begin{array}{l}\text { The ability to monitor and modulate } \\
\text { cognition, emotion, and behavior }\end{array}$ \\
\hline $\begin{array}{l}\text { Metacognitive } \\
\text { awareness }\end{array}$ & $\begin{array}{l}\text { Decentering, } \\
\text { reperceiving }\end{array}$ & $\begin{array}{l}\text { The ability to shift perspective from } \\
\text { the subjective to the objective } \\
\text { nature of a thought }\end{array}$ \\
\hline
\end{tabular}

\section{Mindfulness meditation and attention regulation}

Parsing out attention-regulation styles is as important as understanding the functionality of attentional networks in the elucidation of the mechanisms of MM. In fact, meditation practices are usually described by the degree to which they entail FA, also referred to as concentrative attention, and RA, also referred to as open monitoring (Table 4). ${ }^{19}$ Although sometimes likened specifically to open monitoring, ${ }^{78}$ mindfulness practice is distinguishable by its utilization of both FA and RA. ${ }^{19}$

\section{Focused attention}

FA is restricted to a specific object, which is commonly the sensory experience of the breath going in and out. ${ }^{5}$ Ideally, attention is sustained, but as distractions arise, which can include thoughts, feelings, and physical sensations, a conflict is presented, as different stimuli are pulling for attention. ${ }^{19}$ Initially, it is difficult to maintain FA, yet after repeated practice, more enhanced attentional regulation is ideally developed, ${ }^{19}$ such that sustained attention becomes easier and distractions are less prominent. Therefore, conflict monitoring and redirection of attention are used to a lesser degree..$^{79}$

\section{Receptive attention}

As consistent conflict monitoring becomes increasingly moot, there is less need for a specific object of focus (the breath). Instead, attention is receptive to the entire field of awareness and its "objectless" nature. ${ }^{40,80}$ Distractions are less of an issue with RA, as attention is distributed and extended to all events as they temporally occur. ${ }^{81}$ This context provides a "meta"-awareness of mental processes and creates the space to decenter and cultivate a nonjudgmental attitude to whatever is experienced in an entire field of mental awareness. ${ }^{82}$

Table 4 Attention regulation styles in mindfulness meditation

\begin{tabular}{lll}
\hline $\begin{array}{l}\text { Types of attention } \\
\text { in meditation }\end{array}$ & $\begin{array}{l}\text { Also } \\
\text { known as }\end{array}$ & Definition \\
\hline Focused attention & $\begin{array}{l}\text { Concentrative } \\
\text { meditation }\end{array}$ & $\begin{array}{l}\text { Attention is restricted to a } \\
\text { specific chosen sensory input. } \\
\text { Attention is ideally sustained, } \\
\text { but focused attention also } \\
\text { enables redirecting attention } \\
\text { back to the original focus }\end{array}$ \\
& $\begin{array}{l}\text { Attention is receptive to the } \\
\text { entire field of awareness. OM }\end{array}$ \\
& $\begin{array}{l}\text { Open } \\
\text { monitoring } \\
\text { (OM) }\end{array}$ & $\begin{array}{l}\text { by distributed attention and } \\
\text { nonjudgmental awareness }\end{array}$ \\
& &
\end{tabular}




\section{FA and RA}

In summary, mindfulness practice initially entails increased effort to redirect attention to an explicitly selected neutral object (often, this object is the breath) and ultimately sustain attention upon it. As practice continues (as one becomes more experienced), it becomes increasingly natural, and no explicit object of attention is required. According to Carmody, ${ }^{20}$ repeated practice allows one to notice attentional habits, and by doing so, attentional resources are less automatic. Ultimately, a more reflexive "meta"-awareness of usually implicit mental terrain is cultivated, and concurrent monitoring of multiple present-moment experiences takes place. Often, even with experience, attention is likely focused and broadened many times, as becoming adept at attending to each sensation as it unfolds in the moment is a continued process. ${ }^{83}$ Ultimately, through the utilization of both attentional regulation styles, one is mindful of the present moment, whether it includes a particular object or all salient stimuli.

\section{Rumination}

Rumination has been defined as a passive dwelling upon negative thoughts and emotions, ${ }^{84}$ which is frequently selffocused..$^{85}$ Rumination is akin to a perseverative process, and often leads to a vicious cycle of unintentionally directed attention. In this way, the mind automatically goes from one potentially negative thought to another or to an associated conditioned component. ${ }^{86}$

Overall, increased rumination is negatively correlated with aspects of psychological health ${ }^{87}$ It is a risk factor for the development of depression, ${ }^{88}$ can prolong negative mood, ${ }^{49}$ and has been implicated in depressive relapse. ${ }^{16}$ Although rumination is particularly studied with regard to depressogenic tendencies, Nolen-Hoeksema et a ${ }^{89}$ acknowledged its possible relevance in mediating other psychopathology. More specifically, rumination was found to be a predictor of anxiety, ${ }^{84}$ and is also negatively correlated with measures of self-esteem. ${ }^{90}$ Rumination is often maintained despite its contribution to continued psychological difficulty, because many people view it as an adaptive route to actually solving a problem. ${ }^{91}$ However, research has confirmed that mindfulness is more effective than rumination in coping with dysphoric mood..$^{92}$ Rumination has been linked to distorted interpretation of life events, increased pessimism about the future, and poor interpersonal problem solving. ${ }^{93}$

Rumination has also been associated with attention difficulties; the same populations that exhibit deficits in sustained attention ${ }^{24}$ and set-shifting difficulties ${ }^{25}$ are also more likely to ruminate. ${ }^{26}$ Furthermore, rumination has often been associated with a general tendency to be cognitively inflexible, ${ }^{94}$ as reflected in making more perseverative errors and having more difficulty shifting set. ${ }^{95}$

\section{Mindfulness meditation and reduced rumination}

It was mentioned in this paper's introduction that a vast number of studies had found that MM is related to improved mental health across a variety of disorders. The paper also previously emphasized that knowledge of the underlying mechanisms that contribute to these outcomes is very much limited. There is research that proposes that decreased ruminative thinking is particularly responsible for MM's positive impact on psychological well-being. For example, Teasdale et $\mathrm{al}^{96}$ and Segal et $\mathrm{al}^{97}$ indicated that depressive relapse is prevented with MM practice via decreased rumination fostered by decentering. Ramel et al ${ }^{19}$ suggested that MM decreased ruminative thinking in those with lifetime affective disorders, and that increased practice was related to a trajectory of less rumination. Jain et al ${ }^{99}$ found that in a sample of college students, MM was associated with reduced distress by way of decreased rumination. Chambers et al ${ }^{100}$ found both a negative association between MM and rumination and a direct relationship between MM and effective emotion regulation. Campbell et al ${ }^{101}$ found decreased ruminative processes in women with cancer status after mindfulness training. Michalak et al ${ }^{102}$ studied the effect of an 9-week MBCT program on rumination and relapse in people with major depressive disorder. Their results indicated that increased scores on the Rumination Response Scale significantly predicted relapse, suggesting that rumination has a role in maintaining psychological difficulty.

\section{Attention regulation enables reduced rumination during $M M$}

This review supports MM's role in improved or maintained psychological well-being through the mechanism of reducing rumination via attentional processes. The question remains as to how. This review suggests a two-step process. The first step entails distraction, and the second entails decentering. These steps correspond to the attention-regulation styles inherent to MM, as regulation is at the heart of the potential for changes in psychological functioning. ${ }^{19}$

\section{Distraction and FA}

As mentioned earlier, early on in one's MM practice, when it entails FA, attention is sustained on the neutral sensation 
of the breath. While this skill is being cultivated, ruminative thought processes likely interrupt the effort to sustain this attention. The ability to switch attention (ie, conflict monitoring), however, ensures that one is constantly distracting oneself from ruminative thoughts via redirection of attention from rumination back to the breath. ${ }^{97}$

According to the response styles theory of rumination, distraction is a healthier response to stress than is rumination, and entails a deliberate direction of attention away from ruminative thoughts onto a pleasant or neutral stimulus. ${ }^{23}$ According to Broderick, ${ }^{92}$ distraction can decrease dysphoric mood. Nolen-Hoeksema and Morrow studied the effects of rumination and distraction on depressed mood, and found that subjects in the distraction group became significantly less depressed. Those in the rumination group became significantly more depressed. ${ }^{88}$

Without attentional redirection, the mind automatically elaborates. ${ }^{103}$ Therefore, if one is ruminating on one thought, associated thoughts, feelings, and sensations are likely to be elicited in a vicious cycle. The need for constant directing and redirecting from ruminations to the distraction of focusing on the breath nurtures regulatory processes. ${ }^{104}$ Therefore, it becomes possible to make a more adaptive choice as to where to place attention. ${ }^{86}$ Kabat-Zinn et $\mathrm{al}^{71}$ found that participants in their study placed particular importance on the direction and redirection of attention to the breath in maintaining ongoing psychological well-being well after the study was completed.

However, Nolen-Hoeksema et al noted that distraction is important, but ultimately only serves as temporary relief, because with distraction, avoidance is taking place. In the long term, avoiding and pushing away thoughts through distraction is as inefficient as clinging to them via rumination. ${ }^{89}$

\section{Decentering and RA}

MM utilizes the benefits of distraction, but then goes beyond it in cultivating a more adaptive response to distress. This is enabled through RA, during which attentional focus is broadened and one is encouraged to be aware of all experiences. One now has the space to actually notice patterns of overengagement in negative thoughts, as opposed to suppressing them through distraction.

Wallace and Shapiro ${ }^{105}$ indicated that cognitive flexibility provides "the mental space" with which to identify negative evaluations that would otherwise go unnoticed. Engaging in MM thus adaptively draws attention to negative thoughts, as opposed to suppressing them.

The ability to cultivate a broader range of awareness also cultivates the ability to decenter, which is enabled through enhanced metacognition, and allows for a stepping back from any possible secondary elaboration of ruminative thoughts. Thoughts are nonjudgmentally accepted as just thoughts that come and go. ${ }^{77,106}$

Studies have demonstrated that broadening one's attentional focus is linked to positive emotional states, as thoughts and emotions are seen as fleeting "mental" events, as opposed to accurate representations of reality or reflections of personal truths. In fact, instead of engaging with the thought content, one can simply note, "I am having a thought". When thoughts are seen as transient, one is more likely to feel disconnected to them. Thought processes are now examined from a distance, creating a shift away from "goal-based processing", which actually results in decreased rumination. ${ }^{96}$

During both FA and RA, some kind of shift takes place. During the former, one's ability to distract and redirect attention away from rumination and learn to sustain attention on the neutral breath reflects a literal shift in attention. During the latter, via the ability to decenter, one shifts attention from the content toward the process of a thought. Wallace and Shapiro suggest that this shift is particularly important in maintaining psychological well-being, as a thought becomes a mental event rather than an intrinsic part of one's self. ${ }^{105}$

\section{Summary and future directions}

Given the research conveying MM's impact upon psychological well-being, a growing number of mental health professionals are calling upon a technique with a long and meaningful history and applying its more modern iterations to treatment protocol. Despite the research regarding positive outcomes, specific mechanisms associated with mindfulness and wellbeing are unclear. A more precise look at these mechanisms is important in helping to create profiles of those populations most likely to benefit from MM in clinical settings.

There are many reasons that the mechanisms are somewhat elusive, including the ambiguity in the way mindfulness is operationalized, used, and researched. Research appears to indicate that attentional components likely play a role, and are at least a feasible and parsimonious starting point from which to learn more about how MM leads to positive psychological outcomes. Taking this point further, multiple aspects of attention interact to help decrease ruminative processes, which have been implicated in psychopathology. During FA, distraction by way of conflict monitoring and other regulatory processes enable greater sustained attention. Distraction can only go so far, however, without becoming avoidance. During RA, decentering is cultivated, which is in contrast to distraction, in that one is literally faced with all 
ruminative experiences as they occur in the moment. That vantage point allows for a more objective and less judgmental perspective. This perspective is more adaptive and reflected in greater psychological well-being.

\section{Disclosure}

The author reports no conflicts of interest in this work.

\section{References}

1. Bhikkhu M. A Buddhist model for health care reform. J Med Assoc Thai. 2007;90(10):2213-2221.

2. Ekman P, Davidson RJ, Ricard M, Wallace BA. Buddhist and psychological perspectives on emotions and well-being. Curr Dir Psychol Sci. 2005;14(2):59-63.

3. Thera N. The Heart of Buddhist meditation: A Handbook of Mental Training on the Buddha's Way of Mindfulness. London: Rider; 1962.

4. Silananda U. The Four Foundations of Mindfulness. Boston: Wisdom; 1990.

5. Bishop SR, Lau M, Shapiro S, et al. Mindfulness: a proposed operational definition. Clin Psychol Sci Pract. 2004;11(3):230-241.

6. Keng SL, Smoski MJ, Robins CJ. Effects of mindfulness on psychological health: a review of empirical studies. Clin Psychol Rev. 2011; 31(6):1041-1056.

7. Kim YW, Lee SH, Choi TK, et al. Effectiveness of mindfulness-based cognitive therapy as an adjuvant to pharmacotherapy in patients with panic disorder or generalized anxiety disorder. Depress Anxiety. 2009;26(7):601-606.

8. Hofmann SG, Sawyer AT, Witt AA, Oh D. The effect of mindfulnessbased therapy on anxiety and depression: a meta-analytic review. $J$ Consult Clin Psychol. 2010;78(2):169-183.

9. King AP, Erickson TM, Giardino ND, et al. A pilot study of group mindfulness-based cognitive therapy (MBCT) for combat veterans with posttraumatic stress disorder (PTSD). Depress Anxiety. 2013;30(7): 638-645.

10. Coelho HF, Canter PH, Ernst E. Mindfulness-based cognitive therapy: evaluating current evidence and informing future research. $J$ Consult Clin Psychol. 2007;75(6):1000-1005.

11. Kristeller JL, Baer RA, Quillian-Wolever R. Mindfulness-based approaches to eating disorders. In: Baer RA, editor. Mindfulness and Acceptance-Based Interventions: Conceptualization, Application, and Empirical Support. San Diego: Elsevier; 2006:75-91.

12. Tapper K, Shaw C, Ilsley J, Hill AJ, Bond FW, Moore L. Exploratory randomised controlled trial of a mindfulness-based weight loss intervention for women. Appetite. 2009;52(2):396-404.

13. Bowen S, Witkiewitz K, Dillworth TM, et al. Mindfulness meditation and substance use in an incarcerated population. Psychol Addict Behav. 2006;20(3):343-347.

14. Zeidan F, Gordon NS, Merchant J, Goolkasian P. The effects of brief mindfulness meditation training on experimentally induced pain. $J$ Pain. 2010;11(3):199-209.

15. Wells RE, Yeh GY, Kerr CE, et al. Meditation's impact on default mode network and hippocampus in mild cognitive impairment: a pilot study. Neurosci Lett. 2013;556:15-19.

16. Teasdale JD, Segal Z, Williams JM. How does cognitive therapy prevent depressive relapse and why should attentional control (mindfulness) training help? Behav Res Ther. 1995;33(1):25-39.

17. Brown KW, Ryan RM. The benefits of being present: mindfulness and its role in psychological well-being. J Pers Soc Psychol. 2003;84(4): $822-848$.

18. Shapiro SL, Carlson LE, Astin JA, Freedman B. Mechanisms of mindfulness. J Clin Psychol. 2006;62(3):373-386.

19. Lutz A, Slagter HA, Dunne JD, Davidson RJ. Attention regulation and monitoring in meditation. Trends Cogn Sci. 2008;12(4):163-169.
20. Carmody J. Evolving conceptions of mindfulness in clinical settings. J Cogn Psychother. 2009;23(3):270-280.

21. Hölzel BK, Lazar SW, Gard T, Schuman-Olivier Z, Vago DR, Ott U. How does mindfulness meditation work? Proposing mechanisms of action from a conceptual and neural perspective. Perspect Psychol Sci. 2011;6(6):537-559.

22. Phillipot P, Segal Z. Mindfulness based psychological interventions: developing emotional awareness for better being. J Conscious Stud. 2009;16(10-12):285-306.

23. Nolen-Hoeksema S, Morrow J, Fredrickson BL. Response styles and the duration of episodes of depressed mood. J Abnorm Psychol. 1993;102(1):20-28.

24. Lawrence NS, Ross TJ, Hoffmann R, Garavan H, Stein EA. Multiple neuronal networks mediate sustained attention. $J$ Cogn Neurosci. 2003;15(7):1028-1038.

25. Gehring WJ, Bryck RL, Jonides J, Albin RL, Badre D. The mind's eye, looking inward? In search of executive control in internal attention shifting. Psychophysiology. 2003;40(4):572-585.

26. Treynor W, Gonzalez R, Nolen-Hoeksema S. Rumination reconsidered: a psychometric analysis. Cognit Ther Res. 2003;27(3):247-259.

27. Chiesa A, Serretti A. A systematic review of neurobiological and clinical features of mindfulness meditations. Psychol Med. 2010;40(8): $1239-1252$

28. Winbush NY, Gross CR, Kreitzer MJ. The effects of mindfulness-based stress reduction on sleep disturbance: a systematic review. Explore (NY). 2007;3(6):585-591.

29. Toneatto T, Nguyen L. Does mindfulness meditation improve anxiety and mood symptoms? A review of the controlled research. Can J Psychiatry. 2007;52(4):260-266.

30. Das LS. Awakening the Buddha Within: Eight Steps to Enlightenment. New York: Bantam; 1997.

31. Chiesa A. The difficulty of defining mindfulness: current thought and critical issues. Mindfulness. 2013;4(3):255-268.

32. Baer RA. Mindfulness training as a clinical intervention: a conceptual and empirical review. Clin Psychol Sci Pract. 2003;10(2):125-143.

33. Chiesa A. Vipassana meditation: systematic review of current evidence. J Altern Complement Med. 2010;16(1):37-46.

34. Kang C, Whittingham K. Mindfulness: a dialogue between Buddhism and clinical psychology. Mindfulness. 2010;1(3):161-173.

35. Kabat-Zinn J. Full Catastrophe Living: Using the Wisdom of Your Mind to Face Stress, Pain and Illness. New York: Dell; 1990.

36. Segal ZJ, Williams MG, Teasdale JD. Mindfulness-Based Cognitive Therapy for Depression: A New Approach to Preventing Relapses. New York: Guilford; 2002.

37. Linehan MM. Skills Training Manual for Treating Borderline Personality Disorder. New York: Guilford; 1993.

38. Hayes SC, Strosahl KD, Wilson KG. Acceptance and Commitment Therapy: An Experimental Approach to Behaviour Change. New York: Guilford; 1999.

39. Chiesa A, Calati R, Serretti A. Does mindfulness training improve cognitive abilities? A systematic review of neuropsychological findings. Clin Psychol Rev. 2011;31(3):449-464.

40. Jha AP, Krompinger J, Baime MJ. Mindfulness training modifies subsystems of attention. Cogn Affect Behav Neurosci. 2007;7(2):109-119.

41. Anderson ND, Lau MA, Segal ZV, Bishop SR. Mindfulness-based stress reduction and attentional control. Clin Psychol Psychother. 2007;14(6):449-463.

42. Heeren A, Philippot P. Changes in ruminative thinking mediate the clinical benefits of mindfulness: preliminary findings. Mindfulness. 2010;2(1):8-13.

43. Hargus E, Crane C, Barnhofer T, Williams JM. Effects of mindfulness on meta-awareness and specificity of describing prodromal symptoms in suicidal depression. Emotion. 2010;10(1):34-42.

44. Williams JM, Teasdale JD, Segal ZV, Soulsby J. Mindfulness-based cognitive therapy reduces overgeneral autobiographical memory in formerly depressed patients. J Abnorm Psychol. 2000;109(1): $150-155$. 
45. Slagter HA, Lutz A, Greischar LL, et al. Mental training affects distribution of limited brain resources. PLoS Biol. 2007;5(6):e138.

46. Chambers R, Lo BCY, Allen NB. The impact of intensive mindfulness training on attentional control, cognitive style, and affect. Cognitive Therapy and Research. 2008;32(3):303-322.

47. Zeidan F, Johnson SK, Diamond BJ, David Z, Goolkasian P. Mindfulness meditation improves cognition: evidence of brief mental training. Conscious Cogn. 2010;19(2):597-605.

48. Cusens B, Duggan GB, Thorne K, Burch V. Evaluation of the breathworks mindfulness-based pain management programme: effects on well-being and multiple measures of mindfulness. Clin Psychol Psychother. 2010;17(1):63-78.

49. Wenk-Sormaz H. Meditation can reduce habitual responding. Adv Mind Body Med. 2005;21(3-4):33-49.

50. Ortner CN, Kilner SJ, Zelazo PD. Mindfulness meditation and reduced emotional interference on a cognitive task. Motiv Emot. 2007;31(4): 271-283.

51. Polak E. Impact of two sessions of mindfulness training on attention. 2009. Available from: http://scholarlyrepository.miami.edu/cgi/ viewcontent.cgi? article $=1250 \&$ context $=0 a \_$dissertations. Accessed March 23, 2015.

52. Tang YY, Ma Y, Wang J, et al. Short-term meditation training improves attention and self-regulation. Proc Natl Acad Sci U SA. 2007;104(43): 17152-17156.

53. McMillan TM, Robertson IH, Brock D, Chorlton L. Brief mindfulness training for attentional problems after traumatic brain injury: a randomised control treatment trial. Neuropsychol Rehabil. 2002;12(2): $117-125$.

54. Baer RA, Smith GT, Hopkins J, Krietemeyer J, Toney L. Using selfreport assessment methods to explore facets of mindfulness. Assessment. 2006;13(1):27-45.

55. Farb NA, Anderson AK, Segal ZV. The mindful brain and emotion regulation in mood disorders. Can J Psychiatry. 2012;57(2):70-77.

56. Vago DR, Silbersweig DA. Self-awareness, self-regulation, and self-transcendence (S-ART): a framework for understanding the neurobiological mechanisms of mindfulness. Front Hum Neurosci. 2012;6:296.

57. Chiesa A, Malinowski P. Mindfulness-based approaches: are they all the same? J Clin Psychol. 2011;67(4):404-424.

58. van de Weijer-Bergsma E, Formsma AR, de Bruin EI, Bögels SM. The effectiveness of mindfulness training on behavioral problems and attentional functioning in adolescents with ADHD. J Child Fam Stud. 2012;21(5):775-787.

59. Ellenbogen MA, Schwartzman AE, Stewart J, Walker CD. Stress and selective attention: the interplay of mood, cortisol levels, and emotional information processing. Psychophysiology. 2002;39(6):723-732.

60. Posner MI, Petersen SE. The attention system of the human brain. Annu Rev Neurosci. 1990;13:25-42.

61. Raz A. Translational attention: from experiments in the lab to helping the symptoms of individuals with Tourette's syndrome. Conscious Cogn. 2012;21(3):1591-1594.

62. Posner MI, Rothbart MK. Research on attention networks as a model for the integration of psychological science. Annu Rev Psychol. 2007;58: $1-23$.

63. Dosenbach NU, Petersen SE. Attentional networks. In: Squire LR, editor. Encyclopedia of Neuroscience. Vol 1. Waltham (MA): Academic; 2009:655-660.

64. Petersen SE, Posner MI. The attention system of the human brain: 20 years after. Annu Rev Neurosci. 2012;35:73-89.

65. Fan J, Posner M. Human attentional networks. Psychiatr Prax. 2004; 31 Suppl 2:S210-S214.

66. Posner MI, Rothbart MK. Attention, self-regulation and consciousness. Philos Trans R Soc Lond B Biol Sci. 1998;353(1377):1915-1927.

67. Posner MI, Sheese BE, Odludas Y, Tang Y. Analyzing and shaping human attentional networks. Neural Netw. 2006;19(9):1422-1429.

68. Wadlinger HA, Isaacowitz DM. Fixing our focus: training attention to regulate emotion. Pers Soc Psychol Rev. 2011;15(1):75-102.
69. Berger A, Kofman O, Livneh U, Henik A. Multidisciplinary perspectives on attention and the development of self-regulation. Prog Neurobiol. 2007;82(5):256-286.

70. Vohs KD, Baumeister RF. Handbook of Self-Regulation: Research, Theory and Applications. New York: Guilford; 2004.

71. Kabat-Zinn J, Lipworth L, Burney R. The clinical use of mindfulness meditation for the self-regulation of chronic pain. J Behav Med. 1985;8(2):163-190.

72. Moore A, Malinowski P. Meditation, mindfulness and cognitive flexibility. Conscious Cogn. 2009;18(1):176-186.

73. Mirsky AF, Anthony BJ, Duncan CC, Ahearn MB, Kellam SG. Analysis of the elements of attention: a neuropsychological approach. Neuropsychol Rev. 1991;2(2):109-145.

74. Moore A, Malinowski P. Meditation, mindfulness and cognitive flexibility. Conscious Cogn. 2009;18(1):176-186.

75. Stroop JR. Studies of interference in serial verbal reactions. $J$ Exp Psychol. 1935;18(6):643-662.

76. Flavell JH. Metacognition and cognitive monitoring: a new area of cognitive-developmental inquiry. Am Psychol. 1979;34(10):906-911.

77. Teasdale JD, Moore RG, Hayhurst H, Pope M, Williams S, Segal ZV. Metacognitive awareness and prevention of relapse in depression: empirical evidence. J Consult Clin Psychol. 2002;70(2):275-287.

78. Dunn B, Hartigan JA, Mikulas WL. Concentration and mindfulness meditations: unique forms of consciousness? Appl Psychophysiol Biofeedback. 1999;24(3):147-165.

79. Barinaga M. Buddhism and neuroscience. studying the well-trained mind. Science. 2003;302(5642):44-46.

80. Raffone A, Srinivasan N. The exploration of meditation in the neuroscience of attention and consciousness. Cogn Process. 2010; 11(1): $1-7$

81. Valentine ER, Sweet PL. Meditation and attention: a comparison of the effects of concentrative and mindfulness meditation on sustained attention. Ment Health Relig Cult. 1999;2(1):59-70.

82. Teasdale JD, Segal ZV, Williams JM, Ridgeway VA, Soulsby JM, Lau MA. Prevention of relapse/recurrence in major depression by mindfulness-based cognitive therapy. $J$ Consult Clin Psychol. 2000;68(4):615-623.

83. Hasenkamp W, Wilson-Mendenhall CD, Duncan E, Barsalou LW. Mind wandering and attention during focused meditation: a finegrained temporal analysis of fluctuating cognitive states. Neuroimage. 2012;59(1):750-760.

84. Nolen-Hoeksema S. The role of rumination in depressive disorders and mixed anxiety/depressive symptoms. J Abnorm Psychol. 2000;109(3): 504-511.

85. Smith JM, Alloy LB. A roadmap to rumination: a review of the definition, assessment, and conceptualization of this multifaceted construct. Clin Psychol Rev. 2009;29(2):116-128.

86. Carmody J, Baer RA, Lykins, EL, Olendzki N. An empirical study of the mechanisms of mindfulness in a mindfulness-based stress reduction program. J Clin Psychol. 2009;65(6):613-626.

87. Harrington R, Loffredo DA. Insight, rumination, and self-reflection as predictors of well-being. J Psychol. 2011;145(1):39-57.

88. Nolen-Hoeksema S, Morrow J. Effects of rumination and distraction on naturally occurring depressed mood. Cogn Emot. 1993;7(6):561-570.

89. Nolen-Hoeksema S, Wisco BE, Lyubomirsky S. Rethinking rumination. Perspect Psychol Sci. 2008;3(5):400-424.

90. Rasmussen MK, Pidgeon AM. The direct and indirect benefits of dispositional mindfulness on self-esteem and social anxiety. Anxiety Stress Coping. 2011;24(2):227-233.

91. Lyubomirsky S, Nolen-Hoeksema S. Self-perpetuating properties of dysphoric rumination. J Pers Soc Psychol. 1993;65(2):339-349.

92. Broderick PC. Mindfulness and coping with dysphoric mood: contrasts with rumination and distraction. Cognit Ther Res. 2005;29(5): 501-510.

93. Lyubomirsky S, Nolen-Hoeksema S. Effects of self-focused rumination on negative thinking and interpersonal problem solving. J Pers Soc Psychol. 1995;69(1):176-190. 
94. Hertel PT. Relation between rumination and impaired memory in dysphoric moods. J Abnorm Psychol. 1998;107(1):166-172.

95. Davis RN, Nolen-Hoeksema S. Cognitive inflexibility among ruminators and nonruminators. Cognit Ther Res. 2000;24(6):699-711.

96. Teasdale JD, Segal Z, Williams JM. How does cognitive therapy prevent depressive relapse and why should attentional control (mindfulness) training help? Behav Res Ther. 1995;33(1):25-39.

97. Segal ZJ, Williams MG, Teasdale JD. Mindfulness-Based Cognitive Therapy for Depression: A New Approach to Preventing Relapses. New York: Guilford; 2002.

98. Ramel W, Goldin PR, Carmona PE, McQuaid JR. The effects of mindfulness meditation on cognitive processes and affect in patients with past depression. Cognit Ther Res. 2004;28(4):433-455.

99. Jain S, Shapiro SL, Swanick S, et al. A randomized controlled trial of mindfulness meditation versus relaxation training: effects on distress, positive states of mind, rumination, and distraction. Ann Behav Med. 2007;33(1):11-21.

100. Chambers R, Lo BC, Allen NB. The impact of intensive mindfulness training on attentional control, cognitive style, and affect. Cognit Ther Res. 2007;32(3):303-322.
101. Campbell TS, Labelle LE, Bacon SL, Faris P, Carlson LE. Impact of mindfulness-based stress reduction (MBSR) on attention, rumination and resting blood pressure in women with cancer: a waitlist-controlled study. J Behav Med. 2012;35(3):262-271.

102. Michalak J, Hölz A, Teismann T. Rumination as a predictor of relapse in mindfulness-based cognitive therapy for depression. Psychol Psychother. 2011;84(2):230-236.

103. Damasio A. Mental self: the person within. Nature. 2003;423(6937): 227.

104. Hilt LM, Pollak SD. Getting out of rumination: comparison of three brief interventions in a sample of youth. J Abnorm Child Psychol. 2012;40(7):1157-1165.

105. Wallace BA, Shapiro SL. Mental balance and well-being: building bridges between Buddhism and Western psychology. Am Psychol. 2006;61(7):690-701.

106. Brown KW, Ryan RM, Creswell JD. Mindfulness: theoretical foundations and evidence for its salutary effects. Psychol Inq. 2007;18(4): 211-237.

\section{Publish your work in this journal}

Psychology Research and Behavior Management is an international, peerreviewed, open access journal focusing on the science of psychology and its application in behavior management to develop improved outcomes in the clinical, educational, sports and business arenas. Specific topics covered include: Neuroscience, memory \& decision making; Behavior

\section{Dovepress}

modification \& management; Clinical applications; Business \& sports performance management; Social and developmental studies; Animal studies. The manuscript management system is completely online and includes a quick and fair peer-review system. Visit http://www.dovepress. com/testimonials.php to read real quotes from published authors. 